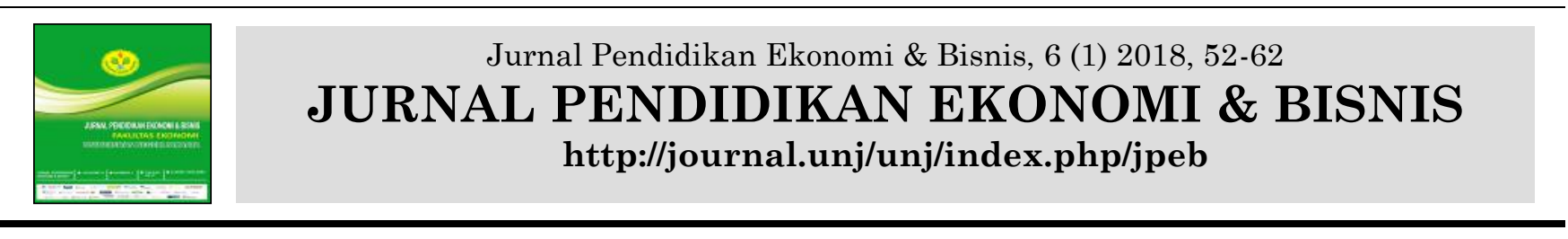

\title{
Strategi Menyiasati Perubahan Bisnis: Kasus BMT Al-Ittihad
}

\author{
Nofrizal $^{1}$, Prama Widayat ${ }^{2^{*}}$ \\ 1 Universitas Lancang Kuning, Riau, Indonesia \\ 2 Universitas Lancang Kuning, Riau, Indonesia
}

\begin{tabular}{l}
\hline Article Info \\
\hline Article history: \\
Received: 2 February 2018; \\
Accepted: 23 February 2018; \\
Published: 1 February 2018. \\
Keywords: \\
Strategic Management; Sharia \\
Cooperative; TWOS Matrix \\
\end{tabular}

\begin{abstract}
This research aims to formulate and select BMT Al-Ittihad Rumbai strategy to face the changing of business environment both from internal environment such as organization resources, finance, member and external business such as competitor, economy, politics and others. This research method used Analysis of EFAS, IFAS, IE Matrix, SWOT-8K Matrix, SPACE Matrix and TWOS Matrix. our hope from this research it can assist BMT Al-Ittihad in formulating and selecting strategies for the sustainability of BMT Al-Ittihad in the future. The sample in this research is manager and leader of BMT Al-Ittihad Rumbai Pekanbaru. The result of this research shows that the position of BMT Al-Ittihad using IE Matrix, SWOT-8K Matrix and SPACE Matrix is in growth position, stabilization and aggressive. The choice of strategy after using TWOS Matrix is market penetration, market development, vertical integration, horizontal integration, and stabilization
\end{abstract}

\begin{abstract}
Abstrak
Penelitian ini bertujuan untuk merumuskan dan memilih strategi BMT Al Ittihad Rumbai dalam menghadapi perubahan lingkungan bisnis baik dari lingkungan internal seperti sumber daya organisasi, keuangan, anggota dan ekternal bisnis seperti pesaing, ekonomi, politik, dan lain-lain. Metode penelitian ini menggunakan Analisis EFAS, IFAS, Matrik IE, Matrik SWOT 8K, Matrik SPACE dan Matrik TWOS. Pengambilan sampel dalam peneltian ini menggunakan teknik purposive sampling yaitu pihak manajer dan pimpinan BMT Al Ittihad Rumbai di Pekanbaru. Hasil penelitian ini menunjukan bahwa posisi strategi BMT Al-Ittihad Rumbai berada pada posisi pertumbuhan, stabilisasi dan agersif. Adapun pilihan strategi setelah mengunakan Matrik TWOS adalah penetrasi pasar, pengembangan pasar, integrasi vertikal, integrasi horizontal, dan stabilisasi
\end{abstract}

How to Cite:

Nofrizal \& Widayat, P. (2018). Strategi Menyiasati Perubahan Bisnis: Kasus BMT Al-Ittihad. Jurnal Pendidikan Ekonomi \& Bisnis, 6(1), 52-62.

https://doi.org/https://doi.org/10.21009/JPEB.006.1.6

* Corresponding Author. 


\section{PENDAHULUAN}

Persaingan koperasi di kota Pekanbaru semakin kompetitif seiring majunya pembangunan suatu daerah dimana koperasi tersebut didirikan. Kota Pekanbaru merupakan kota yang sedangkan berkembang banyak gedung-gedung tinggi telah berdiri dan akan terus bertambah. Kota Pekanbaru juga menjadi tujuan investasi terbaik di Indonesia bagi para investor versi majalah Sindo Weekly (12.com, 2016).

Saat ini jumlah koperasi di kota Pekanbaru yang aktif berjumlah 371 dari tahun sebelumnya hanya 300 dengan jumlah keseluruhan total koperasi 900 koperasi sesuai dengan renstra (Wijaya, W., Yulianeu, Y., Syaifuddin, T., \& Wulan, 2017). Hal ini tentu tidak lepas dari peran pemerintah dalam pengembangan koperasi di kota Pekanbaru. Dinas koperasi dan UMKM di bawah Pemerintah kota Pekanbaru telah meluncurkan beberapa kebijakan untuk membuat koperasi di kota Pekanbaru perkembang dan maju.

Koperasi tidak bisa lepas dengan masyarakat dimana koperasi tersebut didirikan karena masyarakat tersebutlah yang akan menghidupkan koperasi. Dengan menjadi anggota koperasi tersebut maka masingmasing anggota koperasi memiliki perilaku yang berbeda-beda seperti keinginan dan kebutuhan. Jika kebutuhan dan keinginannya terpenuhi maka anggota koperasi akan merasa puas dan menimbulkan loyalitas (Arizal .N, 2016).

BMT Al-Ittihad Rumbai merupakan salah satu lembaga keuangan non bank. Baitul Maal Wat Tamwil (BMT) sebagai lembaga ekonomi yang bermisi memberdayakan pengusaha kecil bawah dan kecil yang menerapkan prinsip syariah, telah terbukti berperan dalam membangun perekonomian masyarakat khususnya lapisan bawah. Dengan semakin meningkatnya perkembangan perekonomian di kota Pekanbaru saat ini dapat dilihat dengan banyak bermunculan lembaga-lembaga keuangan yang menerapakan prinsip syari'at islam seperti perbankan syariah, pegadaian syariah, asuransi syariah, koperasi syariah dan Baitul Maal Wat Tamwil (BMT) di kota Pekanbaru, menyebabkan setiap lembaga keuangan syariah dituntut untuk lebih kreatif dan inovatif, karena semakin ketat tingkat persaingan bisnis non bank untuk bertahan maupun mengalahkan pesaing bisnis.

Dengan semakin banyaknya bermunculan lembaga keuangan non bank yang menyebabkan perubahan perilaku konsumen, maka BMT Al-Ittihad Rumbai tidak bisa hanya berdiam diri saja ditambah posisi BMT Al-Ittihad yang berada dekat dengan komplek Chevron Fasifik Indonesia (CFI), tentu anggota penuh dan sukarela dari BMT Al-Ittihad rata adalah karyawan (CFI) tersebut namun pada tahun 2020 kontrak ekpolarasi akan habis.

Berdasarkan keadaan tersebut maka dibutuhkan sebuah kegiatan formulasi dan implementasi strategi agar BMT Al Ittihad Rumbai yang memulai beroperasi pada 15 juni 2000 dan saat ini memiliki tiga cabang di Kota Pekanbaru dapat bersaing dan bertahan dengan persaingan yang semakin kompetitif.

\section{METODE}

Penelitian ini menggunakan metode kualitatif. Menurut Sugiyono (2011), metode kualitatif mengambarkan dan memahami makna di balik data-data yang tampak. Pada penelitian ini untuk mendapatkan informasi jenis data peneliti menggunakan sumber data primer dan skunder. Pengambilan data menggunakan teknik wawancara, kuesioner, observasi dan kajian literatur.

Analisis data menggunakan pendekatan kualitatif, dengan tahapan sebagai berikut: Penetuan Visi dan Misi, Matrik IFAS (Internal Strategic Factors Analysis Summary) dan Matrik EFAS (External Strategic Factors Analysis Summary) (Wijaya, W., Yulianeu, Y., Syaifuddin, T., \& Wulan, 2017). Untuk menentukan posisi strategi menggunakan Matrik IE (Budiman, C., Massie, J., \& Wullur, 2015), Matrik SWOT8K (Muhammad, 2013) (Nofrizal, 2017), dan Matrik SPACE (Santosa, 2015). Sedangkan untuk pemilihan strategi menggunakan Marik TWOS (Grošelj, P., \& Stirn, 2015). 


\section{HASIL DAN PEMBAHASAAN Hasil}

BMT Al-Ittihad Rumbai adalah pengembangan usaha dari Yayasan Kesatuan Pendidikan Islam (YKPI) Rumbai, dengan melaksanakan prinsip Koperasi sesuai dengan Undang-Undang nomor 25 tahun 1992 tentang Perkoperasian, tetapi memakai prinsip Koperasi Syariah, memulai operasi sejak 15 Juni tahun 2000 dengan nama Baitul Maal Wat Tamwil Al-Ittihad, berbadan hukum tanggal 31 Januari 2001 Nomor. 272/BH/DISKOP\&UKM/3/X/2001, Surat Izin Tempat Usaha (SITU) nomor 517/H/UPT/WK -2003, serta Sertifikat Opersional BMT no- mor 034/PINBUK/Riau/XI/2000, beralamat Komplek Cemara No. 418, Camp PT. CPI, Rumbai Pekanbaru.

Visi yang diusung BMT Al-Ittihad adalah "Menjadi pusat dakwah Islam terpadu untuk mewujudkan masyarakat madani yang sejahtera lahir dan batin serta bahagia dunia dan akhirat". Misi "Memacu pembinanaan umat dalam bidang pengembangan usaha muamalat Islam". Setelah dilakukan analisis menggunakan analisis lingkungan umum dan lingkungan industri yang terdiri dari ekonomi, sosial, politik, lingkungan, teknologi, pesaing, pendatang baru,

Tabel 1. EFAS (External Environment) BMT Al-Ittihad Rumbai

\begin{tabular}{|c|c|c|c|}
\hline $\begin{array}{l}\text { Peluang } \\
\end{array}$ & Bobot & Skala & Skor \\
\hline $\begin{array}{l}\text { Pelaksanaan undang-undang tentang } \\
\text { koperasi dari pemerintah pusat dan } \\
\text { daerah. }\end{array}$ & 0.02 & 4 & 0.08 \\
\hline $\begin{array}{l}\text { Program pemerintah tentang kemajuan } \\
\text { koperasi. }\end{array}$ & 0.02 & 4 & 0.08 \\
\hline $\begin{array}{l}\text { Keadaan ekonomi masyarakat seperti } \\
\text { (Pendapatan, Pengeluaran). }\end{array}$ & 0.12 & 4 & 0.48 \\
\hline $\begin{array}{l}\text { Keadaan dari kondisi keadaan Chevron } \\
\text { dimasa yang akan datang. }\end{array}$ & 0.07 & 4 & 0.28 \\
\hline Terbukanya akses tranportasi jembatan & 0.05 & 3 & 0.15 \\
\hline $\begin{array}{l}\text { Perkembangan dari kenaikan harga } \\
\text { barang terus-menerus (inflasi). }\end{array}$ & 0.09 & 4 & 0.36 \\
\hline $\begin{array}{l}\text { Pertumbuhan pasar yang lambat. } \\
\text { Jumlah penduduk yang berada disekitar }\end{array}$ & 0.05 & 4 & 0.20 \\
\hline $\begin{array}{l}\text { BMT Al-itthad merupakan pangsa pasar } \\
\text { potensial. }\end{array}$ & 0.21 & 4 & 0.84 \\
\hline $\begin{array}{l}\text { Penduduk disekitar BMT Al-Ittihad } \\
\text { Rumbai beragam islam. }\end{array}$ & 0.09 & 4 & 0.36 \\
\hline $\begin{array}{l}\text { Kemajuan teknologi (WA, Internet, } \\
\text { Komputer, dll) yang sangat pesat dalam } \\
\text { upaya meningkatkan efisiensi usaha di } \\
\text { lingkungan BMT Al-Ittihad dan } \\
\text { masyarakat. }\end{array}$ & 0.12 & 4 & 0.48 \\
\hline $\begin{array}{l}\text { Acaman } \\
\text { Jumlah persaingan tinggi antara }\end{array}$ & Bobot & Skala & Skor \\
\hline $\begin{array}{l}\text { lembaga keuangan sejenis dan lembaga } \\
\text { keuangan konvensional lainnya. }\end{array}$ & 0.03 & 4 & 0.12 \\
\hline $\begin{array}{l}\text { Mudahnya lembaga/perorangan } \\
\text { membuka koperasi. }\end{array}$ & 0.04 & 3 & 0.12 \\
\hline $\begin{array}{l}\text { Terdapat banyak produk penganti yang } \\
\text { dapat dipilih masyarakat ketika hendak } \\
\text { menggunakan jasa koperasi. }\end{array}$ & 0.05 & 4 & 0.20 \\
\hline $\begin{array}{l}\text { Daya tawar pembeli memiliki pengaruh } \\
\text { besar terhadap operasi BMT Al-Ittihad } \\
\text { Rumbai. }\end{array}$ & 0.01 & 4 & 0.04 \\
\hline $\begin{array}{l}\text { Terdapat banyak pemasok untuk } \\
\text { mensupport/ mendukung operasional } \\
\text { bisnis BMT Al-Ittihad. }\end{array}$ & 0.03 & 4 & 0.12 \\
\hline
\end{tabular}


pembeli, pemasok, dan produk penganti, maka didapatkan hasi analisis EFAS lingkungan eksternal BMT Al-Ittihad Rumbai ditemukan seperti pada tabel 1 .

Berdasarkan tabel 1 diketahui bahwa kondisi BMT Al-Ittihad sedang berada diposisi positif dengan nilai 3.91, selanjutnya dari nilai peluang ditemukan faktor dari kemajuan teknologi dan keadaan ekonomi yaitu pendapatan masyarakat dalam keadaan yang baik dengan skor 0.48. Ini menunjukkan bahwa BMT Al-Ittihad Rumbai memiliki peluang yang besar untuk menangkap peluang pasar koperasi di Kota Pekanbaru. Dengan kondisi ini juga tentu peluang BMT Al-Ittihad untuk maju dan berkembang akan semakin besar.

Sedangkan pada faktor ancaman diketahui nilai yang memiliki pengaruh besar terhadap masa depan BMT Al-Ittihad Rumbai adalah jumlah persaingan tinggi antara lembaga keuangan sejenis, mudahnya membuka koperasi dan terdapat banyak produk penganti. Dengan kondisi ini BMT Al -Ittihad tidak akan mudah untuk maju dan bersaing, namun ancman ini dapat diatasi dengan memanfaatkan kekuatan yang masih dimiliki yang akan dibahas pada table 2 .

Berdasarkan tabel 2, didapatkan hasil perhitungan internal BMT Al-Ittihad Rumbai menunjukkan hal yang positif sama dengan hasil yang didapatkan pada tabel EFAS sebelumnya. Dari faktor kekuatan diketahui bahwa faktor kekuatan yang paling kuat pengaruhnya adalah memiliki pro-

Tabel 2. IFAS (Internal Environment) BMT Al-Ittihad Rumbai

SDM yang berkualitas.

Kekuatan

Terdapat program pengembangan keahlian dan motivasi terhadap karyawan.

Memiliki program pengembangan karir bagi karyawan.

Memiliki SOP (Standar Operasional Prosedur) dalam menjalankan bisnis.

Terdapat hadiah dan hukuman bagi karyawan yang

berprestasi dan melakukan kesalahan.

Kondisi keuangaan BMT Al-Ittihad saat ini.

Jumlah hutang dengan kemampuan membayar hutang.

Memiliki unit bisnis lain untuk menunjang bisnis BMT Al-

Ittihad selain koperasi.

Memiliki inovasi produk yang ditawarkan kepada

masyarakat/nasabah.

Memiliki segmentasi pasar yang luas untuk produk-produk

BMT Al-Ittihad.

Sudah memiliki fasiltas dan beberapa cabang agar mudah

dijangkau oleh masyarakat/nasabah.

BMT Al-Ittihad sudah dikenal oleh masyarakat luas.

Kemudahan persyaratan menjadi anggota baru.

$$
\text { Kelemahaan }
$$

Kemampuan pelayanan dari karyawan BMT Al-Ittihad

Rumbai.

Keadaan komunikasi antara karyawan dan antara

pimpinan dan karyawan.

Kesejahteraan karyawan selama ini.

Hubungan antara pimpinan dan karyawan.

Implementasi SOP (Standar Operasional Prosedur) yang

telah dibuat oleh pihak manajemen.

Kondisi fisik (Gedung) BMT Al-Ittihad.

Tidak begitu banyak melakukan promosi terhadap

pelanggan baru.

Efektifnya promosi melalui iklan dan koran.

Memiliki program strategi pemasaran yang tersusun dan terporgram.

\begin{tabular}{|c|c|c|}
\hline Bobot & Skala & Skor \\
\hline 0.05 & 4 & 0.20 \\
\hline 0.01 & 3 & 0.03 \\
\hline 0.11 & 3 & 0.33 \\
\hline 0.07 & 3 & 0.21 \\
\hline 0.05 & 3 & 0.15 \\
\hline 0.08 & 3 & 0.24 \\
\hline 0.05 & 3 & 0.15 \\
\hline 0.09 & 1 & 0.09 \\
\hline 0.09 & 3 & 0.27 \\
\hline 0.08 & 4 & 0.32 \\
\hline 0.03 & 3 & 0.09 \\
\hline 0.04 & 3 & 0.12 \\
\hline 0.05 & 4 & 0.20 \\
\hline Bobot & Skala & Skor \\
\hline 0.01 & 3 & 0.03 \\
\hline 0.03 & 3 & 0.09 \\
\hline 0.05 & 3 & 0.15 \\
\hline 0.03 & 3 & 0.09 \\
\hline 0.03 & 3 & 0.09 \\
\hline 0.02 & 3 & 0.06 \\
\hline 0.01 & 3 & 0.03 \\
\hline 0.01 & 3 & 0.03 \\
\hline 0.01 & 3 & 0.03 \\
\hline 1 & & 3.00 \\
\hline
\end{tabular}


gram pengembangan karir bagi karyawan. Kondisi keuangaan BMT Al-Ittihad saat ini dan memiliki segmentasi pasar yang luas untuk produk-produk BMT Al-Ittihad. Sedangkan pada faktor kelemahan ada beberapa yang berpengaruh besar terhadap BMT Al -Ittihad yaitu kesejahteraan karyawan selama ini dan implementasi SOP (Standar Operasional Prosedur) yang telah dibuat oleh pihak manajemen.

Berdasarkan dari faktor-faktor tersebut maka total nilai skor dari BMT Al-Ittihad Rumbai adalah 3.00. Ini berarti kondisi BMT pada saat ini tetap dalam keadaan baik, namun harus tetap dilakukan perbaikan pada bagian kelemahan.

Selain itu dari beberapa kelemahan banyak permasalahan sumber daya manusia (SDM). Oleh karena itu permasalahan ini dapat diselesaikan dengan banyak cara diantaranya membuat pelatihan, pemberian penghargaan dan hukuman atau dapat juga diperbaiki sistem dari rekuitmen karyawaan agar mendapatkan karyawaan yang handal.

Dari hasil perhitungan tabel IFAS dan EFAS didapatkan nilai EFAS sebesar 3.91 dan skor untuk hasil IFAS sebesar 3.00. Apabila dikonversikan kedalam gambar diagram IE Matriks, maka terletak ke dalam kotak 1 dan 5, di mana hasilnya perusahaan masuk ke dalam fase pertumbuhan dan sta- bilitas (growth and stability) lihat tabel 3.

Berdasarkan gambar Matrik IE (table 3) strategi yang dapat digunakan adalah growth (pertumbuhan) melalui konstrasi intragrasi vertikal. Ini berarti BMT Al-Ittihad dapat menggunakan strategi pertumbuhan, strategi integrasi ini merupakan strategi mencari kepemilikian atau meningkatkan kontrol pemasok perusahaan. Strategi tersebut khususnya sesuai ketika pemasok perusahaan tidak handal, terlalu mahal, atau tidak memenuhi kebutuhan perusahaan atau mencari kepemilikan pada distribusi produk kepada pelanggan dengan cara mengakusisi distribusi produk.

Selain menggunakan Matrik IE, pada penelitian ini juga menggunakan Matrik SWOT 8K. Matrik ini memiliki delapan (sub) kuadran. Matrik SWOT-8K bermanfaat untuk merumuskan perencanaan korporat, karena matrik ini akan menunjukan strategi apa yang tepat untuk digunakan. Matrik ini didapatkan dari selisih nilai EFAS dan IFAS. Adapun hasil perhitungan nilai dari selisih peluang dan ancaman dari faktor eksternal adalah nilai 2.71. Sedangkan selisih antara kekuatan dan kelemeahan dari faktor internal dengan nilai 1.80. Berdasarkan hasil tersebut maka dapat disimpulkan bahwa posisi strategi BMT Al-Ittihad Rumbai

Tabel 3. Matrik IE BMT Al-Ittihad Rumbai

\begin{tabular}{|c|c|c|c|}
\hline & $\begin{array}{c}\text { Kuat } \\
(3.0-4.0) \\
\end{array}$ & $\begin{array}{c}\text { Sedang } \\
(0.2-2.99) \\
\end{array}$ & $\begin{array}{c}\text { Lemah } \\
(0.1-1.99)\end{array}$ \\
\hline $\begin{array}{c}\text { Kuat } \\
(3.0-4.0)\end{array}$ & $\begin{array}{l}\text { 1. Growth Konsentra } \\
\text { Melalui Intragrasi } \\
\text { Vertikal }\end{array}$ & $\begin{array}{l}\text { i 2. Growth Konsentrasi } \\
\text { Melalui Intragrasi } \\
\text { Horizontal }\end{array}$ & $\begin{array}{l}\text { 4. Retrachment } \\
\text { Penyehatan }\end{array}$ \\
\hline $\begin{array}{l}\text { Sedang } \\
(0.2-2.99)\end{array}$ & $\begin{array}{l}\text { 5. Stability } \\
\text { Hati-hati }\end{array}$ & $\begin{array}{l}\text { 5. Growth Konsentrasi } \\
\text { Melalui Intragrasi } \\
\text { Horizontal Stability } \\
\text { Tidak ada perubahan } \\
\text { profit strategi }\end{array}$ & $\begin{array}{c}\text { 6. Retrachment } \\
\text { Penutupan Sebagian } \\
\text { Usaha }\end{array}$ \\
\hline $\begin{array}{c}\text { Rendah } \\
(0.1-1.99)\end{array}$ & $\begin{array}{l}\text { 7. Growth } \\
\text { Deversifikasi } \\
\text { Konsentrik }\end{array}$ & $\begin{array}{l}\text { 8. Growth } \\
\text { Deversifikasi } \\
\text { Konglomerat }\end{array}$ & $\begin{array}{c}\text { 8. Retrachment } \\
\text { Bangkrut } \\
\text { atau } \\
\text { Likuidasi }\end{array}$ \\
\hline
\end{tabular}


berada pada strategi pertumbuhan stabil (stable growth strategy) atau berada pada kuadran IA seperti pada gambar 1.

Berdasarkan gambar 1, dapat diambil informasi bahwa strategi yang tepat yang dapat dilakukan oleh BMT Al-Ittihad adalah strategi pertumbuhan stabil (stable growth strategy). Strategi ini bermakna bahwa strategi ini biasanya dilakukan perusahaan yang memiliki item kekuatan yang banyak, sementara mereka berada dalam industri yang tingkat daya tariknya tinggi. Sederhananya, perusahaan sedang memiliki kekuatan atau kemampuan untuk ekspansi, karena kondisi eksternal menarik, dan kondisi internal yang mendukung.

Kemampuan disini bisa saja dalam bentuk sumber dana (bisa dana sendiri maupun dana dari pihak ketiga), atau sumber daya dalam bentuk apapun. Sebagai organisasi bisnis, insting untuk selalu tumbuh memang selalu ada. Ada dua pilhan strategi bertumbuh yaitu konsentrasi (concentraction) dan diversifikasi (diversification).

Selanjutnya menggunakan Matrik SPACE yang terdiri dari kerangka kerja empat kuadran yang terdiri dari strategi agresif, konservatif, defensif, dan komprehensif, dimana keempat kuadran ini mengindikasikan strategi mana yang paling cocok dengan organisasi tertentu. Sumbu Matrik SPACE menggambarkan dua dimensi internal dan dua dimensi eksternal. Dua dimensi internal meliputi kekuatan (financial strength = FS) dan keunggulan kompetitif (competitive advantage $=\mathrm{CA}$ ).

Hasil setelah menggunakan Matrik SPACE dengan melakukan observasi terhadap keempat demensi dan penyebaran kuisioner terhadap BMT Al-Ittihad maka ditemukan bahwa posisi BMT Al-Ittihad Rumbai berada pada posisi agresif dengan nilai total sumbu horizontal 1.75 , sedangkan sumbu vertikal 1.70 seperti tabel 4 dan gambar 1 .

\section{Peluang}



Ancaman

Gambar 1. Matrik Analisis SWOT 8K 
Berdasarkan tabel 4 diketahui bahwa keadaan BMT Al-Ittihad Rumbai dalam keadaan strategi agresif lihat gambar 2 di bawah ini, strategi memiliki makna berarti perusahaan berada pada posisi baik untuk menggunakan kekuatan internalnya guna memanfaatkan peluang eksternal, mengatasi kelemahan internal, dan menghindari ancaman eksternal. Dengan demikian, penetrasi pasar, pengembangan pasar, pengembangan produk, integrasi ke belakang, integrasi ke depan, integrasi horizontal dan diversifikasi konglomerat (diversifikasi konsentrik dan diversifikasi horizontal) dapat menjadi salah satu strategi yang efektif yang dapat digunakan oleh BMT Al-Ittihad Rumbai.

Tahapan terakhir dalam penyusunan strategi BMT Al-Ittihad Rumbai adalah pemilihan strategi menggunakan Matrik TWOS lihat tabel 6 setelah mempertimbangkan Matrik EFAS, Matrik IFAS, Matrik IE, Matrik SWOT 8K dan Matrik SPACE. Ber- dasarkan Matrik TOWS tersebut maka BMT Al-Ittihad Rumbai dapat memilih dan menggunkan beberapa formulasi strategi untuk menjalankan koperasinya di masa yang akan datang yaitu sebagai berikut: (1) memaksimalkan 4 cabang yang dimiliki sekarang dengan cara memberikan pelayanan maksimal kepada nasabah; (2) membuat program-program menarik kepada calon nasabah baru dan lama seperti produk untuk pendidikan anak, umrah dan haji; (3) memaksimalkan program untuk pengembangan SDM untuk meningkatkan kinerja SDM; (4) membuat strategi pertumbuhan dengan cara membuka unit usaha yang berhubungan dengan unit bisnis atau tidak berhubungan dengan unit bisnis; (5) bermitra dengan UKM dan UKMK di kota Pekanbaru; (6) membuat promosi yang manarik kepada calon nasabah baru dan nasabah lama dengan cara melakukan komperasi antara industri koperasi di kota Pekanbaru

Tabel 4. Matrik Space BMT Al-Ittihad Rumbai

\begin{tabular}{|c|c|c|c|}
\hline $\begin{array}{l}\text { Kekutan } \\
\text { Keuangan } \\
\text { (FS) }\end{array}$ & Rating & Stabilitas Lingkungan (ES) & Rating \\
\hline a. ROI & 3 & a.Perubahan Teknologi & -3 \\
\hline b. Leverage & 3 & b.Tekanan Persaingan & -2 \\
\hline c. Likuiditas & 4 & c. Keragaman Permintaan & -1 \\
\hline \multirow{2}{*}{ d. Modal } & 4 & d.Persaingan Harga & -1 \\
\hline & & e. Tingkat Inflasi & -2 \\
\hline $14 / 4$ & 3.50 & $9 / 5$ & -1.8 \\
\hline $\begin{array}{c}\text { Keunggulan } \\
\text { Bersaing } \\
\text { (CA) }\end{array}$ & Rating & Kekuatan Industri (IS) & Rating \\
\hline $\begin{array}{l}\text { Pangsa } \\
\text { Pasar }\end{array}$ & -1 & a. Potensi Pertumbuhan & 3 \\
\hline b. Kualitas & -2 & b. Pemanfaatan Sumber daya & 3 \\
\hline $\begin{array}{l}\text { c. Loyalitas } \\
\text { Pelangga } \\
\mathrm{n}\end{array}$ & -1 & c. Kemudahan Masuk ke Industri & 3 \\
\hline \multirow{3}{*}{$\begin{aligned} \text { d. } & \begin{array}{l}\text { Pengenta } \\
\text { huan } \\
\text { tentang } \\
\text { teknologi }\end{array} \\
& \mathbf{6 / 4}\end{aligned}$} & -2 & d. Produktivitas & 4 \\
\hline & -1.5 & & 3.25 \\
\hline & & $\begin{array}{r}\text { Total Sumbu Horizontal } \\
\text { Total Sumbu Vertikal }\end{array}$ & $\begin{array}{l}1.75 \\
1.70\end{array}$ \\
\hline
\end{tabular}


seperti promosi soal bunga kredit dan kemudahan peminjaman, dan; (7) memberikan pemahaman kepada karyawan bahwa koperasi kita adalah koperasi terbaik di kota Pekanbaru dengan sederetan prestasi dan penghargaan.

\section{Pembahasan}

BMT Al-Ittihad Rumbai merupakan unit badan usaha yang bergerak di bidang simpan dan pinjam dengan konsep koperasi syariah. Dengan kemajuan daerah dan jumlah penduduk yang semakin hari miningkat, maka menjadi peluang bagi pengusaha atau investor serta untuk menangkap peluang ekonomi untuk menghasilkan keuntungan.

Koperasi sebagai sarana pembiayaan yang memiliki sikap gotong royong pun bemunculan termasuk BMT Al-Ittihad sebagai koperasi syariah. Dengan semakin banyaknya bermunculan koperasi dan lembaga keuangan, maka persaingan tidak dapat dihindari. Untuk itu diperlukan strategi guna dapat bersaing dan bertahan dimasa yang akan datang. Hasil dari penelitian ini menunjukan bahwa BMT Al-Ittihad Rumbai berada pada posisi yang baik. Hal ini ditunjukan dengan 3 matrik yaitu Matrik IE, Matrik SWOT 8K dan Matrik SPACE seperti tercantum pada tabel 5 .

Berdasarkan gambar 2 dapat disimpulkan bahwa strategi BMT Al-Ittihad Rumbai berada di posisi sehat. Dengan keadaan tersebut maka BMT Al-Ittihad dapat melakukan banyak hal untuk strategi di masa depan seperti penetrasi pasar, pengembangan pasar, pengembangan produk, integrasi ke belakang, integrasi ke

Tabel 5. Posisi strategis BMT Al-Ittihad mengunakan Matrik IE, Matrik SWOT 8K, Matrik SPACE

\begin{tabular}{ccc}
\hline Matrik IE & Matrik SWOT 8K & SPACE \\
\hline Strategi Growth & Strategi Pertumbuhan \& Stabil & Strategi Agresif \\
Konsetrasi Vertical & (stable Growth & \\
& Strategy & \\
\hline
\end{tabular}

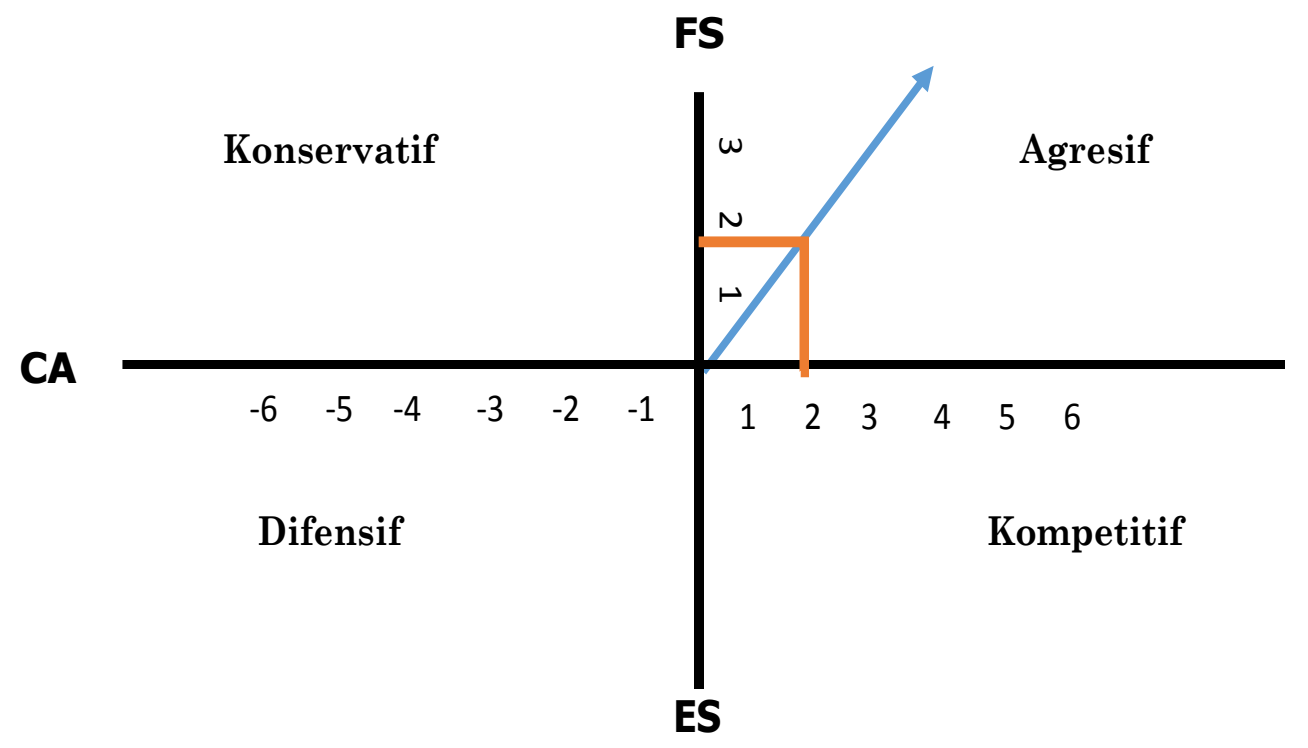

Gambar 3. Matrik SPACE BMT Al-Ittihad Rumbai 
depan (strategi yang dijalankan dengan meraih kendali atas jalur distribusi, mulai dari distributor hingga retailer), integrasi horizontal dan diversifikasi konglomerat.

Strategi-strategi di atas dapat dirumuskan ke dalam Matrik TWOS diantaranya adalah memaksimalkan 4 cabang yang dimiliki sekarang, dengan cara memberikan pelayanan maksimal kepada nasabah dengan membuat program-program menarik kepada calon nasabah baru dan lama seperti produk

Tabel 6.TWOS Matrix BMT Al-Ittihad Rumbai

\begin{tabular}{|c|c|c|}
\hline & 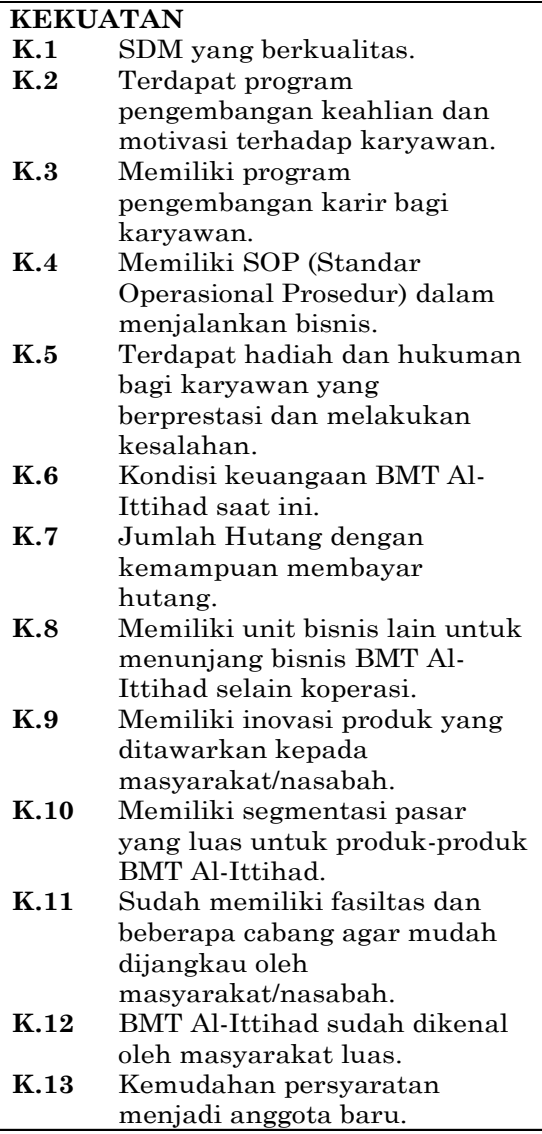 & $\begin{array}{ll}\text { KELEMAHAN } \\
\text { W.1 } \\
\text { Kemampuan pelayanan dari } \\
\text { karyawan BMT Al-Ittihad } \\
\text { Rumbai. } \\
\text { W.2 } \\
\text { Keadaan komunikasi antara } \\
\text { karyawan dan antara pimpinan } \\
\text { dan karyawan. } \\
\text { W.3 } \begin{array}{l}\text { Kesejahteraan karyawan selama } \\
\text { ini. }\end{array} \\
\text { W.4 } \begin{array}{l}\text { Hubungan antara pimpinan dan } \\
\text { karyawan. }\end{array} \\
\text { W.5 Implementasi SOP (Standar } \\
\text { Operasional Prosedur) yang telah } \\
\text { dibuat oleh pihak manajemen. } \\
\text { W.6 } \begin{array}{l}\text { Kondisi fisik (Gedung) BMT Al- } \\
\text { Ittihad. }\end{array} \\
\text { W.7 Tidak begitu banyak melakukan } \\
\text { promosi terhadap pelanggan } \\
\text { baru. }\end{array}$ \\
\hline $\begin{array}{l}\text { PELUANG } \\
\text { P.1 Pelaksanaan undang-undang } \\
\text { tentang koperasi dari pemerintah } \\
\text { pusat dan daerah. } \\
\text { P.2 Program pemerintah tentang } \\
\text { kemajuan koperasi. } \\
\text { P.3 Keadaan ekonomi masyarakat } \\
\text { seperti (Pendapatan, Pengeluaran). } \\
\text { P.4 Keadaan dari kondisi keadaan } \\
\text { Chevron dimasa yang akan datang. } \\
\text { P.5 Terbukanya akses tranportasi } \\
\text { jembatan . } \\
\text { P.6 Perkembangan dari kenaikan } \\
\text { harga barang terus-menurus } \\
\text { (inflasi) } \\
\text { P.7 Pertumbuhan pasar yang tinggi. } \\
\text { P.8 Jumlah penduduk yang berada } \\
\text { disekitar BMT Al-itthad } \\
\text { merupakan pangsa pasar potensial } \\
\text { P.9 Penduduk disekitar BMT Al- } \\
\text { Ittihad Rumbai beragam islam. } \\
\text { P.1O Kemajuan teknologi (WA, } \\
\text { Internet, Komputer, dll) yang } \\
\text { sangat pesat dalam upaya } \\
\text { meningkatkan efisiensi usaha di } \\
\text { lingkungan BMT Al-Ittihad dan } \\
\text { masyarakat }\end{array}$ & $\begin{array}{l}\text { SO STRATEGI } \\
\text { Memaksimalkan 4 cabang yang } \\
\text { dimiliki sekarang dengan cara } \\
\text { memberikan pelayanan } \\
\text { maksimal kepada nasabah } \\
\text { (P10, P5, P2, K6, K9, K10, } \\
\text { K12). } \\
\text { Membuat program-program } \\
\text { menarik kepada calon nasabah } \\
\text { baru dan lama seperti produk } \\
\text { untuk pendidikan anak, umrah } \\
\text { dan haji (P9, P5, P10, K9, } \\
\text { K12, K13). program } \\
\text { Memaksmilakan pDM } \\
\text { untuk pengembangn SDM } \\
\text { untuk meningkatkan kinerja } \\
\text { SDM (K1, K2, K3, P3, P6). } \\
\text { Membuat strategi } \\
\text { pertumbuhan dengan cara } \\
\text { membuka unit usaha yang } \\
\text { berhubungan dengan unit } \\
\text { bisnis atau tidak berhubungan } \\
\text { dengan unit bisnis (K6, K10, } \\
\text { K12, P4). dan } \\
\text { Bermitra dengan UKM dan } \\
\text { UKMK di kota Pekanbaru } \\
\text { (P10, P3, P7, K6, K10). }\end{array}$ & 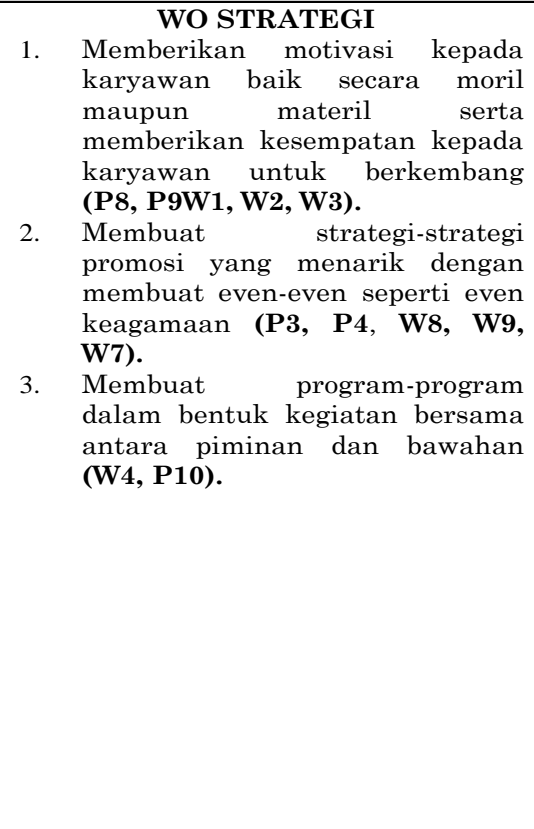 \\
\hline
\end{tabular}


untuk pendidikan anak, umrah dan haji serta memaksimalkan program untuk pengembangn SDM untuk meningkatkan kinerja SDM.

Adapun alasan BMT Al-Ittihad Rumbai harus fokus terhadap memaksimalkan 4 cabang dan meningkatkan kemampuan karyawan, hal ini sesuai dengan penyataan (Supriyadi, 2017) bahwa hasil kajian menunjukkan bahwa motivasi dan manajerial memberikan pengaruh terhadap kinerja karyawan dikerenakan kemampuan keuangan yang cukup baik ditambah jumlah nasabah yang banyak, serta penghargaanhargaan dari pihak pemerintah ataupun lembaga yang dapat menjadi citra yang baik (Alimudin, 2017).

Adapaun cara terbaik untuk menyampaikan ini adalah dengan menggunakan strategi pemasaran sesuai dengan pendapat (Saputro, A. S., Hidayat, K., \& Yulianto, 2016) bahwa hasil penelitian menunjukkan strategi yang sesuai untuk PT. Telkomsel Cabang Malang adalah strategi intensif yang terdiri dari penetrasi pasar, pengembangan pasar, dan pengembangan produk.

\section{KESIMPULAN DAN SARAN}

Dari hasil penelitian ini dapat disimpulkan bahwa BMT Al-Ittihad sebagai koperasi syariah memiliki formulasi strategi BMT Al-Ittihad Rumbai dapat menggunakan strategi pertumbuhan, agresif dan stabilias. Sedangkan posisi strategi BMT AlIttihad Rumbai berada di posisi baik karena berada di kuadran yang positif yaitu agresif, pertumbuhan, dan stabilasi.

Sedangkan dari ketiga matrik yaitu Matrik IE, Matrik SWOT 8K dan Matrik SPACE semua menunjukkan kinerja yang baik dimana disarankan untuk menggunakan strategi pertumbuhan dan stabilisasi setelah diketahui dari analisis Matrik TWOS. Untuk merumuskan strategi, ditemukan beberapa strategi yang dapat dilipilih BMT Al-Ittihad diantranya memaksimalkan 4 cabang yang sudah ada yaitu cabang Rumbai, cabang Panam dan cabang Duri, membuka kerjasama dengan UKM dan UMKM, memaksimalkan kinerja kuangan dengan membuat program-program pem- bukaan unit usaha, dan melakukan program -program atau produk promosi yang berkaitan dengan nilai keagamaan Islam. Sedangkan saran untuk BMT Al-Ittihad Rumbai adalah BMT Al-Ittihad rumbai harus dapat menganalisis lingkungan eksternal dan internal karena lingkungan ini sangat cepat berubah dan terkadang tidak terpredeksi oleh pihak manajemen.

Selanjutnya membuat daftar khususnya untuk pimpinan puncak dan manajer, BMT Al-Ittihad memaksimalkan keunggulan yang dimiliki sekarang seperti citra positif baik pemerintah maupun swasta dan nasabah, BMT Al-Ittihad dapat menggunakan media sosial sebagai alat promosi produk kepada calon nasabah atau pelanggan yang sudah ada, BMT Al-Ittihad dapat menggunakan keuangan yang ada dengan membuat diversifikasi produk kepada masyarakat sesuai dengan kebutuhan masyarakat saat ini. Program-program keagamaan cukup sering dilakukan di kota Pekanbaru ini merupakan peluang baik bagi BMT Al-Ittihad untuk berperan sebagai sponsor guna memperkenalkan produkproduk BMT ke masyarakat kota Pekanbaru.

\section{DAFTAR PUSTAKA}

12.com, R. (2016). Pekanbaru tujuan investasi terbaik di indonesia. Retrieved from http://www.riau12.com/read-501-39212016-03-14-pekanbaru-tujuan-investasiterbaik-di-indonesia.html

Alimudin, A. (2017). "Analisis Pencapaian Strategi Menggunakan Balanced Scorecard." Jurnal Pendidikan Ekonomi \& Bisnis (Edisi Elektronik), 5(2), 178-194.

Arizal .N, N. (2016). Pengaruh Bauran Pemasaran Jasa Terhadap Kepuasan Anggota Pada Koperasi Syariah (Studi Kasus Pada Bmt Al-Ittihad Pekanbaru). Daya Saing, 4(4), 192-199.

Budiman, C., Massie, J., \& Wullur, M. (2015). Identifikasi desain jaringan manajemen rantai pasok kopra di kota manado (studi di kelurahan bengkol dan kelurahan tongkaina). Jurnal EMBA: Jurnal Riset Ekonomi, Manajemen, Bisnis Dan Akuntansi, 3(2). Retrieved 
from https://ejournal.unsrat.ac.id/ index.php/emba/article/view/8356

Grošelj, P., \& Stirn, L. Z. (2015). The environmental management problem of Pohorje, Slovenia: A new group approach within ANP-SWOT framework. Journal of Environmental Management, 161, 106-112. https://doi.org/10.1016/ j.jenvman.2015.06.038

Muhammad, S. (2013). "Manajemen Strategik Konsep dan Alat Analisi.”. Yogyakarta: UPP STIM YKPN.

Nofrizal, N. (2017). Strategi Tumbuh Dan Bersaing Di Industri Asuransi (Studi Kasus Pada BPJS Ketenagakerjaan Pekanbaru). Benefit: Jurnal Manajemen Dan Bisnis, 2(1), 78-91.

Santosa, P. W. (2015). Strategi Bisnis Dengan Menggunakan Analisis Swot Dengan Model Supply Chain Logistik Untuk Meningkatkan Penjualan Retail Pada Pt Xyz. Jurnal Manajemen Bisnis Dan Kewirausahaan, 3(1).

Saputro, A. S., Hidayat, K., \& Yulianto, E. (2016). Perencanaan Strategi Pemasa- ran Paket Data Kampus Dalam Persaingan Di Bidang Paket Data Internet (Studi Kasus Pada Pt. Telkomsel Cabang Malang). Jurnal Administrasi Bisnis, 36(1), 163-169.

Sugiyono. (2011). Metode Penelitian Kuantitatif, kualitatif dan R \& D. Bandung: Alfabeta, 90.

Supriyadi, D. (2017)."Pengaruh Motivasi dan Manajerial terhadap Kinerja Karyawan Bank". Value: Journal of Management and Business, 1(2).

Wijaya, W., Yulianeu, Y., Syaifuddin, T., \& Wulan, H. S. (2017). "Strategi Pengembangan Usaha CV. Steba Advertising Semarang dalam meningkatkan Pendapatan”. Journal of Management, 3(3). 